\title{
Rheumatoid Cachexia: Cytokine-driven Hypermetabolism Accompanying Reduced Body Cell Mass in Chronic Inflammation
}

\author{
Ronenn Roubenoff, ** Rebecca A. Roubenoff, ${ }^{\text {* }}$ Joseph G. Cannon, * Joseph J. Kehayias, " Hong Zhuang, * \\ Bess Dawson-Hughes, ${ }^{\star *}$ Charles A. Dinarello, ${ }^{*}$ and Irwin H. Rosenberg ** \\ ${ }^{*}$ United States Department of Agriculture Human Nutrition Research Center on Aging at Tufts University; and ${ }^{\ddagger}$ Department of Medicine, \\ New England Medical Center, Boston, Massachusetts 02111
}

\begin{abstract}
The cytokines IL-1 $\beta$ and TNF- $\alpha$ cause cachexia and hypermetabolism in animal models, but their role in human inflammation remains controversial. The relationship between in vitro cytokine production and metabolism was examined in 23 adults with RA and 23 healthy control subjects matched on age, sex, race, and weight. Body composition was measured by multicompartmental analysis of body cell mass, water, fat, and bone mass. Resting energy expenditure (REE) was measured by indirect calorimetry. Cytokine production by PBMC was measured by radioimmunoassay. Usual enefgy intake, physical activity, disability scores, medication use, and other confounders were also measured.
\end{abstract}

Body cell mass was 13\% lower $(P<0.00001)$, REE was $12 \%$ higher $(P<0.008)$, and physical activity was much lower $(P<0.001)$ in subjects with RA. Production of TNF- $\alpha$ was higher in RA than controls, both before and after stimulation with endotoxin $(P<0.05)$, while production of IL-1 $\beta$ was higher with endotoxin stimulation $(P<0.01)$. In multivariate analysis, cytokine production was directly associated with REE $(P<0.001)$ in patients but not in controls. While energy and protein intake were similar in the two groups and exceeded the Recommended Dietary Allowances, energy intake in subjects with RA was inversely associated with IL-1 $\beta$ production $(P<$ 0.005).

In this study we conclude that: loss of body cell mass is common in RA; cytokine production in RA is associated with altered energy metabolism and intake, despite a theoretically adequate diet; and TNF- $\alpha$ and IL-1 $\beta$ modulate energy metabolism and body composition in RA. (J. Clin. Invest. 1994. 93:2379-2386.) Key words: body composition • interleukin-1 • tumor necrosis factor • energy • metabolism

\section{Introduction}

Cachexia, from the Greek "bad condition," generally connotes a state of advanced malnutrition and wasting. However, more recently cachexia has been used to denote the loss of body cell

\footnotetext{
+ Deceased.

Address correspondence to Ronenn Roubenoff, M.D., M.H.S., Body Composition Laboratory, USDA HNRCA, 711 Washington Street, Boston, MA 02111.

This work was presented in part at the American College of Rheumatology in Atlanta, GA on 13 October 1992, and at the Federation of American Societies of Experimental Biology meeting in New Orleans, LA on 1 April 1993.

Received for publication 4 October 1993 and in revised form 25 January 1994
}

The Journal of Clinical Investigation, Inc.

Volume 93, June 1994, 2379-2386 mass $(\mathrm{BCM})^{1}$ which occurs in illness (1). $\mathrm{BCM}$ accounts for over $95 \%$ of body metabolic activity (2). The most important aspect of this categorization is that loss of $\mathrm{BCM}$ is a very powerful predictor of outcome in starvation, critical illness, and normal aging (3). Loss of BCM is a hallmark of aging, and a decline in BCM, and especially muscle mass, is seen in both men and women after age 60 (4). In all clinical situations in which it has been studied (5-7), loss of $>40 \%$ of baseline BCM is associated with death. This has led us $(8)$ and others $(1,9)$ to suggest that loss of BCM is an important marker of physiologic health and a potential nonchronologic marker of aging.

Loss of BCM presumably requires a net catabolic process, with negative energy, protein, and micronutrient balances over some period of time. These losses may occur over days to weeks in critical illness, over months to years in chronic illness, and over decades in physiologic aging. Losses that occur over prolonged periods of time are not measurable with standard balance techniques and often can only be detected indirectly by measurement of body composition changes. In trying to understand the mechanisms behind cachexia, the mediators of catabolism in infectious, neoplastic, and inflammatory conditions have been studied extensively. For example, serum from septic humans can cause catabolism when incubated with muscle from healthy rats $(10,11)$. Since septic sera contain TNF- $\alpha$ and IL- $1 \beta$, it has been suggested that these are the inflammatory mediators that lead to loss of BCM in cancer and infectious diseases such as AIDS $(1,11-13)$. However, other studies have failed to show a direct catabolic effect of these cytokines in animals, and the existence of other mediators has been postulated (14-16). We examined these questions in a chronic inflammatory condition, RA.

We chose to study RA for several reasons. First, high levels of TNF- $\alpha$ and IL- $1 \beta$ have been demonstrated in synovial fluid and in circulation of patients with $\operatorname{RA}(17,18)$. Also, mortality in RA exceeds that in the general population by two- to fivefold (19-21). In addition, RA does not typically cause malabsorption or hepatic or renal disease (22), greatly simplifying the study of the impact of chronic inflammation on nutritional and metabolic parameters. Furthermore, we have shown previously that adults with RA have reduced BCM, a form of the "rheumatoid cachexia" first described by Sir James Paget (2325). However, while Paget and most rheumatologists since have considered rheumatoid cachexia to be very unusual on the basis of clinical observation alone, evidence for loss of BCM was found in two-thirds of our subjects. In addition, serum TNF- $\alpha$ levels were elevated during disease flare only in

1. Abbreviations used in this paper: ACR, American College of Rheumatology; BCM, body cell mass; c.v., coefficient of variation; FM, fat mass; LBM, lean body mass; NSAID, nonsteroidal antiinflammatory drug; REE, resting energy expenditure; TBK, total body potassium; TBW, total body water; TSH, thyroid-stimulating hormone. 
those subjects who had lost BCM, but not in apparently equally affected patients with normal BCM, suggesting that cytokine production could be driving the loss of BCM seen in RA (24). The current study was designed both to quantify the extent of loss of BCM and to investigate possible causes of this loss.

\section{Methods}

Study design. A cross-sectional study was conducted on 23 subjects with RA and 23 matched controls. Each subject was studied once.

Study population. Subjects with RA were recruited from the rheumatology clinics at New England Medical Center and affiliated rheumatology practices. All subjects met the American College of Rheumatology (ACR) criteria for RA (26). Cases were matched to healthy controls on the basis of age (within $5 \mathrm{yr}$ ), sex, race, and weight (within 5 $\mathrm{kg}$ ). RA disease severity was assigned before knowledge of outcomes was available, based on the ACR criteria for functional status in RA (27). Subjects who met ACR functional class 1 criteria were considered as mild, class 2 as moderate, and class 3 or 4 as severe $R A$. In contrast to severity, disease activity was carefully controlled: all subjects with RA had to be considered by their rheumatologist to be under good disease control, without change in medication dosage over the previous $3 \mathrm{mo}$. Potential subjects were excluded if they had diarrhea, proteinuria, serum creatinine over $1.3 \mathrm{mg} / \mathrm{dl}$, or abnormal liver transaminases; otherwise subjects were recruited sequentially without selection by weight, body habitus, or disease duration. 15 of the RA subjects were not taking prednisone at the time of study; 9 of these participants had never taken prednisone. 10 of the RA subjects were not taking nonsteroidal antiinflammatory medications (NSAID).

Body composition. Body composition was determined by measuring four bodily compartments independently. BCM was determined by potassium- 40 whole body counting, which relies on the ability to measure total body potassium (TBK), the main intracellular cation, by detecting the amount of naturally radioactive potassium -40 present in the body. The coefficient of variation (c.v.) for TBK at our institution is $<3 \%(8)$. Total body water (TBW) was measured by tritium dilution (c.v. 2\% [28]). Bone mineral mass was measured by dual-energy x-ray absorptiometry (model DPX; Lunar Radiation Corp., Madison, WI) (c.v. $0.6 \%$ [29]), and fat was measured by the same method (c.v. $1.7 \%$ [29]). This approach does not make assumptions about the hydration of lean body mass (LBM) that may be erroneous in RA or in the elderly; calculations of LBM or fat mass (FM) based on TBW were not done to avoid such potential errors. Furthermore, by measuring each compartment independently, the measurement error of one compartment is not propagated to another compartment (8). Compartments were not summated because there is overlap between TBW and BCM. Comparisons between cases and controls were performed using unadjusted data and also after adjusting for stature using knee height, which is not influenced by osteoporotic loss of vertebral height which may be biased between cases and controls (30).

Cytokine production. PBMC were obtained from whole blood by Ficoll-Hypaque centrifugation as described previously and washed three times in sterile, pyrogen-free saline $(31,32)$. Cells were suspended at $5 \times 10^{6} / \mathrm{ml}$ in RPMI (Sigma Chemical Co., St. Louis, MO) which had been subjected to ultrafiltration (33) to remove cytokine-inducing substances. Ultrafiltered RPMI was supplemented with indomethacin $(50 \mu \mathrm{g} / \mathrm{ml}), 100 \mu \mathrm{g} / \mathrm{ml}$ streptomycin, and $100 \mathrm{U} / \mathrm{ml}$ penicillin (Sigma Chemical Co.) and contained 2\% autologous heat-inactivated serum. Cells were cultured in 24-well flat-bottomed plates; each well contained $0.5 \mathrm{ml}$ of cells plus $0.5 \mathrm{ml}$ of RPMI or Escherichia coli endotoxin (B55:0; Sigma Chemical Co.) at 1,10 , or $100 \mathrm{ng} / \mathrm{ml}$. After $22 \mathrm{~h}$ at $37^{\circ} \mathrm{C}$ in $5 \% \mathrm{CO}_{2}$, the plates were frozen at $-80^{\circ} \mathrm{C}$. Plates were thawed and frozen three times to lyse the cells.

Measurement of total IL- $1 \beta$ and TNF- $\alpha$ synthesis was carried out in duplicate by specific, non-cross-reacting radioimmunoassays as described previously $(31,34)$. Dilutions of the lysates from stimulated cells were made to obtain measurements in the $40-70 \%$ portion of the standard curves. Unstimulated cell lysates were assayed undiluted. The RIA for IL- $1 \beta$ detects both the precursor as well as processed IL-1 $\beta$ (35). The interassay variability for samples was $<10 \%$, and the intraassay variability was $\leq 5 \%$ for both cytokines. Lysates from patient and control cells were measured in the same assay.

Energy expenditure. Resting energy expenditure (REE) was measured by indirect calorimetry. Oxygen consumption and carbon dioxide production were measured over 20 min under thermoneutral conditions in the morning after an overnight fast of 10-12 h. The measurements were made after subjects rested supine for $30 \mathrm{~min}$. The subjects were instructed to relax and avoid hyperventilation, fidgeting, and sleeping during measurements. The measurements were made while the subjects breathed through a low-resistance mouthpiece. Expired air was collected in a calibrated Tissot spirometer and an open-circuit respiratory collection system (Warren E. Collins, Inc., Braintree, MA). Oxygen consumption was measured using an oxygen sensor and an oxygen analyzer (N-22M and S-3A, respectively; Applied Electrochemistry, Sunnyvale, $\mathrm{CA}) . \mathrm{CO}_{2}$ production was measured using a medical gas analyzer (LB-2; Beckman Instruments, Inc. Anaheim, CA). Values for REE were calculated using Weir's equation (36).

Physical activity was estimated using the Paffenbarger questionnaire (37). Subjects were asked to estimate the number of hours they usually spent in various activities, separately for weekdays and weekends. Activities were grouped by strenuousness into light, moderate, and heavy; specific examples of each were given; and the questionnaire was reviewed with the subject for clarity and understanding. The number of hours per day that subjects reported they spent in each activity is presented. Self-reported hours of sleep were also determined by questionnaire for weekdays and weekends.

Other measurements. Usual dietary intake was measured by a food frequency questionnaire (Health Habits and History Questionnaire [38]), validated previously by seven nonconsecutive 24-h diet histories in patients with RA (Roubenoff, R., L. W. Grimme, and R. A. Roubenoff, unpublished observations). The correlation between the food frequency instrument and the validation was 0.80 for energy and 0.68 for protein intake, which is typical of the correlations seen with such instruments (39). Disability was measured using the disability and pain scales of the Health Assessment Questionnaire (40). Smoking, medication, income, and education histories were obtained by questionnaire. Complete blood count, Westergren sedimentation rate, serum albumin, and thyroid-stimulating hormone (TSH RIA; Nichols Institute, San Juan Capistrano, CA) were measured by the Human Nutrition Research Center's Nutrition Evaluation Laboratory using standard commercial techniques.

Data analysis. All reported values are means \pm SD unless otherwise noted. Comparisons between groups (cases and controls) used paired $t$ tests and Wilcoxon tests, as appropriate for each variable depending on its distribution. Dose-response trends were tested using ANOVA for trends. Comparison of REE between groups after adjustment for BCM was carried out using analysis of covariance. Analysis was carried out using BMDP programs (BMDP Statistical Software, Inc., Los Angeles, CA). Within-group analyses of the effect of cytokines and other variables on body composition, energy expenditure, and energy intake were carried out using multiple linear regression techniques to create population-specific models that were as simple as possible. Separate analysis of RA and control groups is presented as a more conservative approach than combining all subjects in a single model, where unmeasured differences in case status could skew the analysis, particularly with respect to cytokine variables, which do not have normally distributed residuals if cases and controls are combined into a single population. Categorical variables were created for sex $($ female $=0$, male $=1$ ) and for RA severity ( mild $=1$, moderate $=2$, severe $=3$ ). Models included terms for age and sex when there was preexisting reason to expect these variables to be biologically important with respect to the outcomes examined, even if they did not happen to reach statistical significance in some models. Statistical significance was taken at $\alpha$ $=0.05$. 


\section{Results}

\section{Study population}

In total, 46 subjects were studied, 23 cases and 23 controls. Within each group, there were 19 women and 4 men. Matching was successful on all four categories of matching, as shown in Table I. Within the case group, there were 5 subjects with mild disease, 10 with moderate disease severity, and 8 with severe RA, as defined by ACR criteria for functional status (27). Disease activity at the time of study was low in all subjects, who were taking stable doses of medication and had sedimentation rates and durations of morning stiffness that suggest good disease control (Table I and Methods). 15 of the 23 patients were taking NSAID, 8 were taking prednisone, 2 were taking parenteral gold, 11 oral methotrexate, 3 hydroxychloroquine, and 3 sulfasalazine. Thus, the study population presents a spectrum of disease severity, but uniformly low disease activity, in keeping with the recruitment goals. No subject had clinical evidence of malabsorption, and all had normal serum levels of folate and $B_{12}$, glucose, hepatic transaminases, blood counts, and TSH. The erythrocyte sedimentation rate in the patients was approximately double that in the controls $(35.2$ vs $17.7 \mathrm{~mm} / \mathrm{h}, P$ $<0.001$ ), while serum albumin was lower but still within the normal range ( 40.1 vs $44.5 \mathrm{~g} /$ liter, $P<0.001$ ).

\section{Body composition}

Although weight was not significantly different between cases and controls (Table I), both unadjusted TBK ( 97.7 [cases] vs $115.2 \mathrm{~g}$ [controls], $P<0.00001)$ and stature-adjusted (30) TBK were lower in cases than controls ( $1.93 \mathrm{vs} 2.23 \mathrm{~g}$ of K/cm knee height, $P<0.00001$ ). The difference in stature-adjusted TBK was $13 \%$, or approximately one-third of what is thought to be survivable loss (8). When TBK was converted to kilograms of BCM using the equations of Cohn et al. (41), the

Table I. Characteristics of Cases with RA and Matched Controls

\begin{tabular}{|c|c|c|c|}
\hline Characteristic & Cases & Controls & $P$ \\
\hline Number & 23 & 23 & - \\
\hline Age* $^{*}$ & $50 \pm 15$ & $50 \pm 17$ & NS \\
\hline $\operatorname{Sex}\left(M: F^{*}\right)$ & $4: 19$ & $4: 19$ & NS \\
\hline Race $\left(B: W^{*}\right)$ & $2: 21$ & $2: 21$ & NS \\
\hline Weight $\left(k g^{*}\right)$ & $69.7 \pm 15.9$ & $72.4 \pm 17.3$ & NS \\
\hline Height $(\mathrm{cm})$ & $161.8 \pm 7.5$ & $165.3 \pm 6.0$ & 0.09 \\
\hline No. swollen joints & $4.5 \pm 6.3$ & $0 \pm 0$ & 0.000 \\
\hline No. painful joints & $4.1 \pm 7.2$ & $0 \pm 0$ & 0.000 \\
\hline Morning stiffness $(h)$ & $1.1 \pm 1.6$ & $0 \pm 0$ & 0.000 \\
\hline Pain scale $(\mathrm{cm}[0-15])$ & $6.3 \pm 4.2$ & $0 \pm 0$ & 0.000 \\
\hline Fatigue scale ( $\mathrm{cm}[0-15])$ & $7.3 \pm 4.4$ & $1.8 \pm 0.8$ & 0.000 \\
\hline Duration of RA $(y r)$ & $12.3 \pm 8.4$ & - & - \\
\hline \multicolumn{4}{|l|}{$\begin{array}{l}\text { Mean prednisone dose } \\
\quad(m g[n=8 \text { subjects }\end{array}$} \\
\hline taking prednisone]) & $9.9 \pm 5.4$ & $0 \pm 0$ & 0.000 \\
\hline Hematocrit (\%) & $38.4 \pm 4.1$ & $39.9 \pm 4.3$ & 0.09 \\
\hline Albumin ( $g /$ liter) & $40.1 \pm 4.1$ & $44.5 \pm 3.9$ & 0.01 \\
\hline Serum vitamin B12 $(\mathrm{pg} / \mathrm{ml})$ & $457.9 \pm 198.7$ & $411.0 \pm 195.6$ & NS \\
\hline Serum folate $(n g / m l)$ & $13.2 \pm 10.4$ & $13.3 \pm 4.9$ & NS \\
\hline Rheumatoid factor titer & $1: 60 \pm 1: 10$ & $0 \pm 0$ & 0.000 \\
\hline Sedimentation rate $(\mathrm{mm} / \mathrm{h})$ & $35.2 \pm 24.4$ & $17.7 \pm 11.5$ & 0.001 \\
\hline
\end{tabular}

* Matched variables. Data shown are mean \pm SD.
Table II. Outcome Variables and Important Confounders in Subjects with RA and in Matched Controls

\begin{tabular}{|c|c|c|c|}
\hline Outcome & Cases & Controls & $P$ \\
\hline \multicolumn{4}{|l|}{ Body compartments } \\
\hline $\mathrm{BCM}(k g)$ & $22.5 \pm 4.3$ & $26.6 \pm 5.3$ & $<0.00001$ \\
\hline TBW (liters) & $29.9 \pm 6.2$ & $35.8 \pm 6.8$ & $<0.003$ \\
\hline \multicolumn{4}{|l|}{ Bone mineral } \\
\hline content $(k g)$ & $2.3 \pm 0.5$ & $2.8 \pm 0.5$ & $<0.002$ \\
\hline FM $(k g)$ & $27.8 \pm 9.6$ & $25.5 \pm 12.9$ & NS \\
\hline \multicolumn{4}{|l|}{ REE } \\
\hline $\begin{array}{l}\mathrm{kcal} / \mathrm{d} \text { (unadjusted) } \\
(\mathrm{mJ} / \mathrm{d})\end{array}$ & $\begin{array}{c}1407 \pm 292 \\
(5978 \pm 1241)\end{array}$ & $\begin{array}{c}1413 \pm 218 \\
(6004 \pm 922)\end{array}$ & NS \\
\hline \multicolumn{4}{|l|}{$\mathrm{kcal} / \mathrm{d}$ (adjusted } \\
\hline $\begin{array}{l}\text { for BCM) } \\
(\mathrm{mJ} / \mathrm{d})\end{array}$ & $\begin{array}{c}1488 \pm 169 \\
(6322 \pm 725)\end{array}$ & $\begin{array}{c}1332 \pm 209 \\
(5714 \pm 897)\end{array}$ & $<0.008$ \\
\hline \multicolumn{4}{|l|}{ Energy intake } \\
\hline $\begin{array}{l}\mathrm{kcal} / \mathrm{d} \\
(\mathrm{mJ} / \mathrm{d})\end{array}$ & $\begin{array}{c}1780 \pm 697 \\
(7654 \pm 2997)\end{array}$ & $\begin{array}{c}1997 \pm 623 \\
(8587 \pm 2679)\end{array}$ & NS \\
\hline $\begin{array}{l}\text { kcal/kg per } \mathrm{d} \\
(\mathrm{mJ} / \mathrm{kg} \text { per } \mathrm{d})\end{array}$ & $\begin{array}{l}25.5 \pm 10.0 \\
(110 \pm 43)\end{array}$ & $\begin{array}{l}27.9 \pm 8.7 \\
(120 \pm 37)\end{array}$ & NS \\
\hline \multicolumn{4}{|l|}{ Protein intake } \\
\hline $\mathrm{g} / \mathrm{d}$ & $71.9 \pm 23.7$ & $79.0 \pm 28.7$ & NS \\
\hline $\mathrm{g} / \mathrm{kg}$ per $\mathrm{d}$ & $1.0 \pm 0.3$ & $1.1 \pm 0.2$ & NS \\
\hline \multicolumn{4}{|l|}{ Cigarette smoking } \\
\hline No. cigarettes/d & $4.6 \pm 10.7$ & $1.7 \pm 3.6$ & NS \\
\hline$\%$ Smokers & $22 \%$ & $13 \%$ & \\
\hline \multicolumn{4}{|l|}{ Serum TSH } \\
\hline$\mu \mathrm{IU} / \mathrm{ml}(0.3-5.0)$ & $1.638 \pm 0.737$ & $1.867 \pm 0.966$ & NS \\
\hline \multicolumn{4}{|l|}{ Physical activity } \\
\hline Vigorous $(h / d)$ & $0.1 \pm 0.2$ & $1.5 \pm 1.5$ & $<0.0001$ \\
\hline Moderate $(h / d)$ & $4.0 \pm 3.2$ & $5.6 \pm 2.3$ & $<0.06$ \\
\hline Light $(h / d)$ & $11.6 \pm 3.4$ & $9.2 \pm 3.2$ & $<0.02$ \\
\hline \multicolumn{4}{|l|}{ Sleep } \\
\hline Weekday $(h / d)$ & $8.0 \pm 1.3$ & $7.3 \pm 1.0$ & $<0.03$ \\
\hline Weekend $(h / d)$ & $8.6 \pm 2.4$ & $7.8 \pm 0.9$ & $<0.11$ \\
\hline
\end{tabular}

mean difference in BCM between groups was $4.1 \mathrm{~kg}$ (Table II). There were also significant differences in TBW (29.9 vs 35.8 liters, $P<0.003)$ and bone mineral mass $(2.34$ vs $2.78 \mathrm{~kg}, P$ $<0.002$ ), but not FM (27.8 vs $25.5 \mathrm{~kg}, P=\mathrm{NS}$ ). In addition, there was a strong dose response between RA severity and amount of BCM adjusted for stature using knee height: the more severe the arthritis, the lower the BCM $(P=0.0003$, ANOVA for trend). There was no correlation, however, between BCM and duration of RA, dose of prednisone, highestever dose of prednisone, or dose-years of prednisone.

To examine the potential influence of corticosteroid therapy further, stature-adjusted TBK was examined in four groups: those who had never taken prednisone; those who had taken prednisone previously but were not currently doing so; those who were currently taking prednisone, and the control group. While there was a small difference in BCM between those patients taking prednisone and those who had never taken this medication, this was dwarfed by the magnitude of the difference between controls and subjects with RA (Fig. 1). Furthermore, there was a significant association between the number of subjects considered to have severe RA (ACR functional class 3-4) and prednisone use $\left(\chi^{2}=10.3, P=0.03\right)$, 


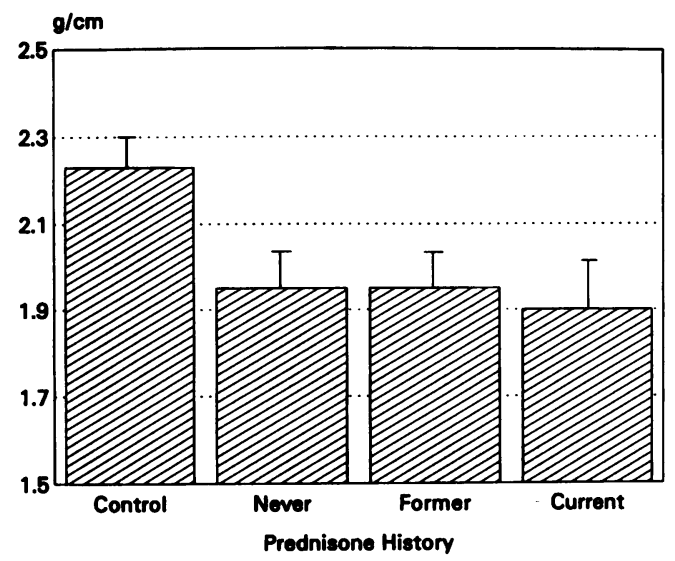

Figure 1. Mean ( \pm SEM) stature-adjusted BCM for control subjects and subjects with RA by prednisone history (never took prednisone, took prednisone previously but not within the past $6 \mathrm{mo}$, or currently taking prednisone).

suggesting that some of the decline in BCM associated with prednisone use may in fact be due to disease severity.

\section{Cytokine production}

Production of TNF- $\alpha$ was higher in PBMC's from subjects with RA than from controls. This was observed in unstimulated cells and in cells stimulated with all three concentrations of endotoxin ( $P<0.05$, Fig. 2$)$. Similarly, mean IL-1 $\beta$ production was higher in cells from patients with RA than controls, but the differences were only statistically significant at 1 and 10 $\mathrm{ng} / \mathrm{ml}$ of endotoxin $(P<0.01$, Fig. 2$)$.

\section{$R E E$, dietary energy intake, and physical activity}

Although absolute REE was not different between subjects with RA and controls (mean $\mathrm{REE}=1,413 \mathrm{vs} 1,410 \mathrm{kcal} / \mathrm{d}, P$ $=\mathrm{NS}$ ), REE was higher in cases than controls after adjustment for BCM (mean adjusted REE $=1,489$ vs $1,332 \mathrm{kcal} / \mathrm{d} ; P$ $<0.008$, analysis of covariance; see Fig. 3 and Table II). Furthermore, REE increased with RA severity, just as BCM fell ( $P$ $<0.0003$, ANOVA for trend). Cigarette smoking, which can

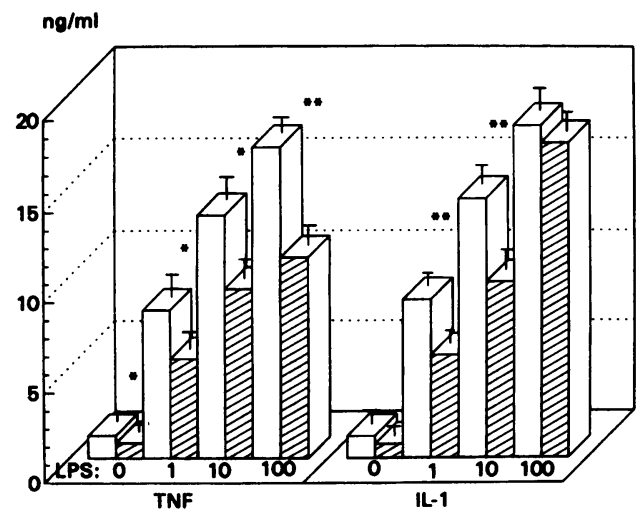

Figure 2. Production of TNF- $\alpha$ (left) and IL-1 $\beta$ (right) in subjects with RA (open bars) and in controls (hatched bars) with increasing concentration of LPS (nanograms per milliliter). Significant differences between RA and control cells were seen for TNF at all four levels of stimulation and for IL-1 at 1 and $10 \mathrm{ng}$ LPS only. ${ }^{*} P<0.05$; *** $P<0.01$.

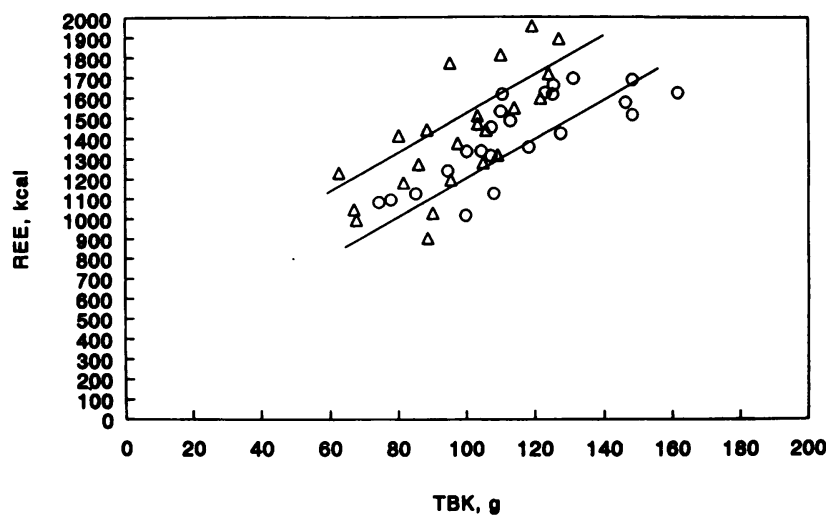

Figure 3. REE (kilocalories per day) vs BCM based on TBK (grams) for subjects with RA (open triangles) and controls (open circles). Difference between the two groups is significant $(P<0.008$, analysis of covariance).

influence REE, did not differ between cases and controls ( $P$ $<0.38)$. TSH levels were normal in all subjects and did not differ between cases and controls $(P<0.30)$. There was no difference between RA and control groups in mean energy or protein intake (Table II). As expected, subjects with RA reported less physical activity than controls by Paffenbarger questionnaire (Table II), especially for vigorous activity ( 0.1 vs $1.5 \mathrm{~h}, P<0.0001$ ), and longer sleeping hours than controls ( 8.0 vs $7.3 \mathrm{~h}, P<0.03)$.

\section{Multivariate analysis}

Multivariate linear regression was used to analyze biologically plausible parameters that explained significant amounts of the variability in REE and energy intake (Table III).

$R E E$. In the control subjects, only $\mathrm{BCM}$ and sex were significant explanatory variables, with higher REE in men. This was consistent with the concept that sex is a surrogate marker for muscle mass, which is an important determinant of REE. In the subjects with RA, in contrast, BCM, IL- $1 \beta$, and TNF- $\alpha$ production by unstimulated PBMCs and the interaction between IL- $1 \beta$ and TNF- $\alpha$ (IL-1 $\times$ TNF) were all significant explanatory variables. The signs of the coefficients were positive, indicating that the higher the basal cytokine production the higher the REE. Sex was not a significant covariate in the RA group. The following were not significant explanatory variables in these models: prednisone dose, duration of RA, NSAID use, methotrexate use, smoking, sedimentation rate, dietary energy intake, or physical activity. Cytokine production (IL-1, TNF, and IL-1 $\times$ TNF) accounted for $20 \%$ of the variability in REE in the cases, while BCM accounted for $57 \%$ of the variability (Table III, column 5).

Energy intake. Within the RA group, sex, use of NSAID, and IL-1 $\beta$ production by stimulated PBMC were each associated significantly with energy intake, after adjustment for age and BCM. IL- $1 \beta$ and sex accounted for $20 \%$ of the variability in energy intake in subjects with RA, while taking NSAID accounted for $9.6 \%$ (Table III, column 5 ). The following were not significant explanatory variables in these models: disease duration, prednisone dose, smoking, physical activity, income, or education. In the control group, no significant explanatory variables were found for this outcome. 
Table III. Multivariate Linear Regression Models for the Outcomes of REE and Energy Intake, Presented Separately for Cases with RA and for Controls

\begin{tabular}{|c|c|c|c|c|c|}
\hline Outcome variable & Explanatory variables & $\beta$ & $\operatorname{SE}(\beta)^{*}$ & Partial $\mathbf{R}^{2}$ & $P$ \\
\hline \multirow[t]{10}{*}{$\operatorname{REE}(k c a l / d)$} & Cases: & & & & \\
\hline & Age $(y r)$ & 3.05 & 2.67 & 0.0167 & NS \\
\hline & $\mathrm{BCM}(g T B K)$ & 11.43 & 2.13 & 0.5734 & $<0.001$ \\
\hline & Basal TNF- $\alpha(n g / m l)$ & 213.14 & 57.99 & 0.0238 & $<0.001$ \\
\hline & Basal IL-1 $\beta(n g / m l)$ & 287.15 & 83.71 & 0.0022 & $<0.001$ \\
\hline & TNF- $\alpha \cdot$ IL- $1 \beta$ & -192.34 & 51.31 & 0.1857 & $<0.001$ \\
\hline & Controls: & & & & \\
\hline & Age $(y r)$ & 0.66 & 2.03 & 0.0147 & NS \\
\hline & $\operatorname{Sex}(F=0 ; M=1)$ & -281.71 & 130.25 & 0.0788 & $<0.025$ \\
\hline & $\mathrm{BCM}(g T B K)$ & 11.47 & 2.30 & 0.6200 & $<0.001$ \\
\hline \multirow[t]{10}{*}{ Energy intake $(\mathrm{kcal} / \mathrm{d})$} & Cases: & & & & \\
\hline & Age $(y r)$ & -11.5 & 8.5 & 0.0209 & NS \\
\hline & $\operatorname{Sex}(F=0 ; M=1)$ & 777.7 & 326.8 & 0.1972 & $<0.01$ \\
\hline & $\mathrm{BCM}(g T B K)$ & -11.0 & 7.7 & 0.0722 & NS \\
\hline & NSAID $($ yes $=1 ;$ no $=0$ ) & 504.6 & 244.9 & 0.0959 & $<0.025$ \\
\hline & Stim. IL-1 $\beta(n g / m l)$ & -41.3 & 15.3 & 0.2001 & $<0.005$ \\
\hline & Controls: & & & & \\
\hline & Age $(y r)$ & -11.5 & 9.5 & 0.0300 & NS \\
\hline & $\operatorname{Sex}(F=0 ; M=1)$ & 612.8 & 613.2 & 0.0460 & NS \\
\hline & $\mathrm{BCM}(g T B K)$ & 0.26 & 10.8 & 0.1403 & NS \\
\hline
\end{tabular}

* SE ( $\beta)$, standard error of the regression coefficient $\beta$.

\section{Discussion}

Data from starvation, cancer, AIDS, and critical illness suggest that loss of $\sim 40 \%$ of BCM is fatal (for reviews see references 1 and 8 ). The results of this study indicate that BCM was $13 \%$ lower in adults with RA than in controls matched on age, sex, race, and weight, suggesting that approximately one-third of mobilizable BCM has been lost in these patients with clinically well controlled RA. These data are the first to quantify the extent of what we have previously termed rheumatoid cachexia. In addition, there was a strong dose-response association between severity of arthritis as estimated by ACR functional class and BCM. Note that functional class is not a measure of disease activity in this group of patients with well controlled arthritis. This loss of BCM may be due to cytokinemediated catabolism, reduced physical activity, inadequate intake, and medication effects. The analyses presented here suggest that all four factors contribute to some extent to rheumatoid cachexia, but demonstrate for the first time an important effect of cytokine-mediated catabolism. While loss of bone mass is well described in RA $(42,43)$, analysis of multiple compartments in this chronic inflammatory condition has not been attempted before.

Elevated production of TNF- $\alpha$ and IL- $1 \beta$ has been described in RA during times of disease activity $(17,18)$. However, it is generally not possible to find detectable levels of cytokines during times of disease quiescence (23). Nevertheless, we were able to demonstrate increased cytokine production by PBMC from subjects with RA. By studying cytokine production by PBMC, we avoided many methodologic problems associated with measuring circulating cytokines, such as those posed by binding proteins, rheumatoid factor, etc. (44). In addition, because it is thought that much of the effect of cytokines occurs in a paracrine or autocrine fashion, circulating levels may not be accurate reflections of the in vivo activity of cytokines at the tissue level; if levels are undetectable, this does not prove that the cytokine is not in fact acting locally. Measurement of cytokine production by unstimulated and stimulated PBMC appears to us to be the best compromise between precision and validity. It would also be of great interest to examine cytokine production by synovial cells rather than PBMC; this was not done in the present study to minimize invasiveness, as joint effusions were uncommon in this patient group with clinically controlled disease.

In addition, after adjustment for BCM, REE was signifcantly higher in our subjects with chronic inflammation, even when their condition was clinically well controlled. In multivariate analysis, we found that higher IL- $1 \beta$ and TNF- $\alpha$ production was associated with increased REE in the RA group, suggesting that excessive production of inflammatory cytokines is linked to hypermetabolism. The finding of hypermetabolism and loss of BCM associated with cytokine production has been demonstrated in animals $(13,45-47)$ and in cytokine infusion studies in humans $(12,48)$. However, this study demonstrates for the first time an association between REE and in vitro cytokine production by PBMC, without intravenous administration of cytokine. The presence of this association even in a group with low disease activity suggests that the hypermetabolism of chronic inflammation smolders even when good clinical control of RA is achieved.

The inverse association between IL- $1 \beta$ production and energy intake in subjects with RA may also be important. The role of inflammation in suppressing appetite has been demonstrated in animals $(46,49)$, but has not been demonstrated clearly in humans. We found no overall difference in energy intake between patients and controls (Table II); however, the 
inverse association between IL- $1 \beta$ production and dietary intake suggests that cytokine production may lead to a relative, rather than absolute, anorexia. In the RA group, IL- $1 \beta-$ induced relative anorexia may aggravate the loss of $\mathrm{BCM}$ that occurs in the hypermetabolic state by preventing patients from increasing their intake to meet their higher energy needs. These data also suggest that IL- $1 \beta$ and TNF- $\alpha$ have different but reinforcing metabolic effects in chronic inflammation. Some caution should be exercised in interpreting these data, as self-reported intakes are subject to many errors (39). However, there is no indication that these errors introduce a bias in dietary assessment between cases and controls (see Methods).

In addition to cytokine-associated elevated REE and relative reduction in intake, a third important determinant of rheumatoid cachexia may be reduced physical activity. As expected, our subjects with RA demonstrated markedly lower levels of vigorous physical activity compared with controls and moderately lower levels of moderate and light activity. Subjects with RA also slept longer hours than controls, although the sleep disturbances that occur in RA (50) may also lead to higher REE during sleep in RA. It should be noted that because we relied on self reports of physical activity and sleep, these results could be biased if patients systematically over or under report their activities compared with controls. However, it is more likely that a patient with RA would consider as "vigorous" what a healthy person would consider "moderate" than the reverse, resulting in a bias against finding an association rather than in its favor. With respect to dietary intake, we have previously validated our instrument in adults with RA and found no bias in reporting intake compared with healthy subjects (51). We hypothesize that the combination of dietary, physical activity, and metabolic abnormalities acts to increase catabolic stimuli while reducing anabolic ones and leads to the loss of BCM seen in rheumatoid cachexia.

We found no direct association between low BCM and increased cytokine production, although both conditions occurred in the RA group. This is not surprising for several reasons. First, changes in BCM occur over months to years, while cytokine production changes from day to day, although between-subject variability is greater than intra-subject day-today variation (31). In contrast, changes in REE occur on the same time scale as changes in BCM. For this reason, our a priori hypothesis was to relate cytokine production to REE rather than BCM. We hypothesize that the hypermetabolism in the face of no increase in intake in turn leads to erosion of BCM. Second, we have shown previously (24) that hypercytokinemia is greatest during disease flare. Thus, we expect that hypermetabolism, relative anorexia, and erosion of BCM accelerate during times of heightened disease activity. This study was designed to include people with well controlled disease and could not test this hypothesis. Third, many $(46,47,49)$ but not all (14) animal studies offer biologic plausibility to the association between cytokine production and cachexia, but these longitudinal infusion studies are difficult or impossible to perform in humans. In one human study (12), TNF administration led to doubling of forearm amino acid efflux, a metabolic derangement that would predispose to cachexia. Finally, from a statistical point of view, this study did not have adequate power to reject a null hypothesis of no association between differences in cytokine production within case-control pairs and differences in BCM, because of the nonnormal distribution of residuals of differences in cytokine production. Thus, we conceptualize change in BCM as the "area under the curve" of a person's metabolic state: as such, it is the summation of their cytokine status over many years at different levels of disease activity that we would expect to correlate with BCM and not their cross-sectional production on the day of study.

There are several other limitations of this study. First, the small sample size, dictated by the technologically intensive nature of the work, suggests that replication in other populations is needed. For example, larger-scale studies of body composition in RA could be undertaken using bioelectrical impedance, based on population-specific equations derived from the data presented here. Second, the contribution of other mediators of body composition and energy expenditure, such as growth hormone, androgens, and cortisol, was not studied, although thyroid status was within normal limits in all subjects.

Third, the potential effect of corticosteroids and other medications in these results should not be ignored. Our results apply to patients with RA who are treated in the conventional manner. Eight of our subjects with RA were taking prednisone at the time of the study, with a mean dose of $9.9 \mathrm{mg} / \mathrm{d}$ (Table I). Since cytokine production is reduced by prednisone, it is unlikely that the results seen here are due to corticosteroid effects (52). Although glucocorticoids play a role in the loss of body calcium seen in RA $(42,43)$, their effect on BCM is less clear. Body composition was abnormal in RA patients regardless of steroid status (Fig. 1), and prednisone was not a significant explanatory variable for REE (Table III). However, prednisone dose is a strong marker of disease severity (Fig. 1), and we cannot evoke a scenario in which people with RA can be studied completely free of steroid or other drug effects. Svenson et al. $(53,54)$ have shown that metabolic parameters in RA are abnormal during inflammation and are normalized by the use of low-dose corticosteroids. While we have shown that highdose "pulse" corticosteroids cause obligate loss of nitrogen in people with RA (23), low-dose oral glucocorticoids may be protective of LBM by reducing inflammation and improving functional status to a greater extent than they cause catabolism (24). Further, it is unlikely that either methotrexate or azathioprine would affect energy metabolism in RA, as recent data suggest that even much higher doses of these medications do not alter REE in humans (55).

Furthermore, although very high doses of aspirin (5,500 $\mathrm{mg} / \mathrm{d}$ ) can increase REE, this effect has not been seen with other NSAID at antiinflammatory doses (56). In our population, no effect of NSAID on REE was seen in multivariate linear regression ( Table III). Moreover, the effect of NSAID on in vitro cytokine production was abrogated since indomethacin was added to cultures of cells of patients and controls. This has been shown to reduce the effects of oral NSAID without affecting the rank order of subjects with respect to cytokine production (31). The mechanism by which NSAID increased dietary intake in our subjects with RA remains speculative: perhaps reduction of prostaglandin production improved appetite, or it may be that patients with RA were following instructions to take their NSAID with food to reduce the risk of NSAID gastropathy.

These data support the concept that chronic inflammation can lead to hypermetabolism and relative anorexia and predispose to loss of BCM in humans. The changes in body composition occurring in RA are identical to those seen in many other chronic illnesses as well as in normal aging (8). Further study of the interactions between production of inflammatory cyto- 
kines, body composition, and physiologic function should increase our understanding of these changes in health and disease.

\section{Acknowledgments}

The authors thank Helen Rasmussen and Jacqueline Charnley for administering food frequency questionnaires; Patricia Engel for nutritional services; Dr. William J. Evans for his advice and support; Dr. Susan Roberts for review of the typescript; Arlene Tenney for assistance with recruitment; Brenda Crawford for technical assistance; and the staff of the Nutrition Evaluation Laboratory and the nursing staff of the Metabolic Research Unit at the Human Nutrition Research Center for their capable and devoted assistance. This work is dedicated to the memory of the late Rebecca Roubenoff, who knew it could be done.

This study was supported in part by National Institutes of Health grants DK-08443 (R. Roubenoff) and AG-00209 (R. A. Roubenoff), the Pew National Nutrition Fellowship (R. Roubenoff), and the United States Department of Agriculture Contract 53-3K06-5-10 (I. H. Rosenberg).

The contents of this publication do not necessarily reflect the views or policies of the U.S. Department of Agriculture nor does mention of trade names, commercial products, or organizations imply endorsement by the U.S. Government.

\section{References}

1. Grunfeld, C., and K. R. Feingold. 1992. Metabolic disturbances and wasting in the acquired immunodeficiency syndrome. $N$. Engl. J. Med. 327:329-337. 2. Moore, F. D. 1980 . Energy and the maintenance of body cell mass. $J$. Parenter. Enteral Nutr. 4:228-260.

3. Cahill, G. F. 1972. Starvation in man. N. Engl. J. Med. 282:668-675.

4. Borkan, G. A., and A. H. Norris. 1977. Fat redistribution and the changing body dimensions of the adult male. Human. Biol. 49:495-514.

5. Winick, M., editor. 1979. Hunger Disease. John Wiley \& Sons, New York. $261 \mathrm{pp}$.

6. Kotler, D. P., A. R. Tierney, and R. N. Pierson. 1989. Magnitude of body cell mass depletion and the timing of death from wasting in AIDS. Am. J. Clin. Nutr. 50:444-447.

7. DeWys, W. D., C. Begg, P. T. Lavin, P. R. Band, J. M. Bennett, J. R. Bertino, M. H. Cohen, H. O. Douglass, P. F. Engstrom, D. Z. Ezdinli, et al. 1980. Prognostic effect of weight loss prior to chemotherapy in cancer patients. Am. J. Med. 69:491-497.

8. Roubenoff, R., and J. J. Kehayias. 1991. The meaning and measurement of lean body mass. Nutr. Rev. 46:163-175.

9. Heymsfield, S. B., R. A. Bethel, J. D. Ansley, D. W. Nixon, and D. Rudman. 1979. Enteral hyperalimentation: an alternative to central venous hyperalimentation. Ann. Intern. Med. 90:63-71.

10. Clowes, G. H. A., B. C. George, C. A. Villee, and C. A. Saravis. 1983. Muscle proteolysis induced by a circulating peptide in patients with sepsis or trauma. N. Engl. J. Med. 308:545-552.

11. Baracos, V., H. P. Rodemann, C. A. Dinarello, and A. L. Goldberg. 1983. Stimulation of muscle protein degradation and prostaglandin E2 release by leukocytic pyrogen (interleukin-1). N. Engl. J. Med. 308:553-558.

12. Warren, R. S., H. F. Starnes, J. L. Gabrilove, H. F. Oettgen, and M. F. Brennan. 1987. The acute metabolic effects of tumor necrosis factor administration in humans. Arch. Surg. 122:1396-1400.

13. Moldawer, L. L., M. A. Rogy, and S. F. Lowry. 1992. The role of cytokines in cancer cachexia. J. Parenter. Enteral Nutr. 16:43S-49S.

14. Moldawer, L. L., G. Svaninger, J. Gelin, and K. G. Lundhom. 1987. Interleukin-1 and tumor necrosis factor do not regulate protein balance in skeletal muscle. Am. J. Physiol. 253 (Cell Physiol. 22).C766-C773.

15. Michie, H. R., M. L. Sherman, D. R. Spriggs, J. Rounds, M. Christie, and D. W. Wilmore. 1989. Chronic TNF infusion causes anorexia but not accelerated nitrogen loss. Ann. Surg. 209:19-24.

16. Grunfeld, C., H. Wilking, R. Neese, L. A. Gavin, A. H. Moser, R. Gulli, M. K. Serio, and K. R. Feingold. 1989. Persistence of the hypertrigliceridemic effect of tumor necrosis factor despite development of tachyphylaxis to its anorectic/cachectic effects in rats. Cancer Res. 49:2554-2560.

17. Eastgate, J. A., N. C. Wood, F. S. DiGiovine, J. A. Symons, F. M. Grinlinton, and G. W. Duff. 1988. Correlation of plasma interleukin-1 levels with disease activity in rheumatoid arthritis. Lancet. ii:706-709.

18. Saxne, T., M. A. Palladino, D. Heinegard, N. Talal, and F. A. Wollheim.
1988. Detection of tumor necrosis factor- $\alpha$ but not tumor necrosis factor- $\beta$ in rheumatoid arthritis synovial fluid and serum. Arthritis Rheum. 31:1041-1044.

19. Pincus, T., and L. F. Callahan. 1986. Taking mortality in rheumatoid arthritis seriously: predictive markers, socioeconomic status, and comorbidity. $J$. Rheumatol. 13:841-845.

20. Symmons, D. P. M. 1988. Mortality in rheumatoid arthritis. Br. J. Rheumatol. 27:44-54.

21. Jacobsson, L. T. H., W. C. Knowler, S. Pillemer, R. L. Hanson, D. J. Pettitt, R. G. Nelson, A. del Peunte, D. R. McCance, M.-A. Charles, and P. H. Bennett. 1993. Rheumatoid arthritis and mortality. A longitudinal study in Pima Indians. Arthritis Rheum. 36:1045-1053.

22. Harris, E. D. 1989. The clinical features of rheumatoid arthritis. In Textbook of Rheumatology. 3rd ed., vol. 1. W. N. Kelley, E. D. Harris, S. Ruddy, and C. B. Sledge, editors. W. B. Saunders Co., Philadelphia 943-981.

23. Roubenoff, R., R. A. Roubenoff, L. M. Ward, and M. B. Stevens. 1990. Catabolic effects of high-dose corticosteroids persist despite therapeutic benefit in rheumatoid arthritis. Am. J. Clin. Nutr. 52:1113-1117.

24. Roubenoff, R., R. A. Roubenoff, L. M. Ward, S. M. Holland, and D. B. Hellmann. 1992. Rheumatoid cachexia: depletion of lean body mass in rheumatoid arthritis. Possible association with tumor necrosis factor. J. Rheumatol. 19:1505-1510

25. Paget, J. 1873. Nervous mimicry of organic diseases. Lancet. ii:727-729. 26. Arnett, F. C., S. M. Edworthy, D. A. Bloch, R. J. McShane, J. F. Fries N. S. Cooper, L. A. Healey, S. R. Kaplan, M. H. Liang, H. S. Luthra, et al. 1988. The American Rheumatism Association 1987 revised criteria for the classification of rheumatoid arthritis. Arthritis Rheum. 31:432-442.

27. Hochberg M. C., R. W. Chang, I. Dwosh, S. Lindsey, T. Pincus, and F. Wolfe. 1992. The American College of Rheumatology 1991 revised criteria for the classification of global functional status in rheumatoid arthritis. Arthritis Rheum. 35:498-502.

28. Pierson, R. N., J. Wang, W. Colt, and P. Neumann. 1982. Body composition measurements in normal man: the potassium, sodium, sulfate, and tritium spaces in 58 adults. J. Chronic Dis. 35:419-428.

29. Johnson, J., and B. Dawson-Hughes. 1991. Precision and stability of dualenergy x-ray absorptiometry measures. Calcif. Tissue Int. 49:174-178.

30. Roubenoff, R., and P. W. F. Wilson. 1993. Advantage of knee height over height as an index of stature in expression of body composition in adults. Am. J. Clin. Nutr. 57:609-613.

31. Endres, S., J. G. Cannon, R. Ghorbani, R. A. Dempsey, S. D. Sisson, G. Lonnemann, J. W. M. van der Meer, S. M. Wolff, and C. A. Dinarello. 1989. In vitro production of IL- $1 \beta$, IL- $1 \alpha$, TNF, and IL-2 in healthy subjects: distribution, effect of cyclooxygenase inhibition and evidence of independent gene regulation. Eur. J. Immunol. 19:2327-2333.

32. Schindler, R., B. D. Clark, and C. A. Dinarello. 1990. Dissociation between interleukin- $1 \beta$ mRNA and protein synthesis in human peripheral blood mononuclear cells. J. Biol. Chem. 265:10232-10237.

33. Dinarello, C. A., G. Lonnemann, R. Maxwell, and S. Shaldon. 1987. Ultrafiltration to reject human interleukin-1-inducing substances derived from bacterial cultures. J. Clin. Microbiol. 25:1233-1238.

34. van der Meer, J. W. M., S. Endres, G. Lonnemann, J. G. Cannon, T. Ikejima, S. Okusawa, J. A. Gelfand, and C. A. Dinarello. 1988. Concentrations of immunoreactive human tumor necrosis factor- $\alpha$ produced by human mononuclear cells in vitro. J. Leukocyte Biol. 43:216-223.

35. Cannon, J. G., J. W. M. van der Meer, D. Kwiatkowski, S. Endres, G. Lonnemann, J. F. Burke, and C. A. Dinarello. 1988. Interleukin-1 $\beta$ in human plasma: optimization of blood collection, plasma extraction, and radioimmunoassay methods. Lymphokine Res. 7:457-467.

36. Weir, J. B. de V. 1949. New method for calculating metabolic rate with special reference to protein metabolism. J. Physiol. 109:1-9.

37. Paffenbarger, R. S., R. T. Hyde, A. L. Wing, and C.-C. Hsieh. 1986 Physical activity, all-cause mortality, and longevity of college alumni. $N$. Engl. J. Med. 314:605-613.

38. Block, G., A. M. Hartman, C. M. Dresser, M. D. Carroll, J. Gannon, and L. Gardner. 1986. A data-based approach to diet questionnaire design and testing. Am. J. Epidemiol. 124:453-469.

39. Block, G., and A. M. Hartman. 1989. Issues in reproducibility and validity of dietary studies. Am. J. Clin. Nutr. 50:1133-1138.

40. Fries, J. F. 1982. The dimensions of health outcomes: the Health Assessment Questionnaire. J. Rheumatol. 9:786-793.

41. Cohn, S. H., K. J. Ellis, D. Vartsky, A. Sawitsky, W. Gartenhaus, S. Yasumura, and A. N. Vaswani. 1981. Comparison of methods of estimating body fat in normal subjects and cancer patients. Am. J. Clin. Nutr. 34:2839-2847.

42. Reid, D. M., N. S. J. Kennedy, M. A. Smith, P. Tothill, and G. Nuki. 1982. Total body calcium in rheumatoid arthritis: effects of disease activity and corticosteroid treatment. Br. Med. J. 285:330-332.

43. Dykman, T. R., O. S. Gluck, W. A. Murphy, T. J. Hahn, and B. H. Hahn. 1985. Evaluation of factors associated with glucocorticoid-induced osteopenia in patients with rheumatic diseases. Arthritis Rheum. 28:361-368.

44. Cannon, J. G., J. L. Nerad, D. D. Poutsiaka, and C. A. Dinarello. 1993. Measuring cytokine levels. J. Appl. Physiol. 75:1897-1902. 
45. Tocco-Bradley, R., M. Goerogieff, C. T. Jones, L. L. Moldawer, C. A. Dinarello, G. L. Blackburn, and B. R. Bistrian. 1987. Changes in energy expenditure and fat metabolism in rats infused with interleukin-1. Eur. J. Clin. Invest. 17:504-510.

46. Hellerstein, M. K., S. N. Meydani, M. Meydani, K. Wu, and C. A. Dinarello. 1989. Interleukin-1-induced anorexia in the rat. Influence of prostaglandins. J. Clin. Invest. 84:228-235.

47. Hoshino, E., C. Pichard, C. E. Greenwood, G. C. Kuo, R. G. Cameron, R Kurian, J. P. Kearns, J. P. Allard, and K. N. Jeejeebhoy. 1991. Body composition and metabolic rate in rat during continuous infusion of cachectin. Am. J. Physiol. 260 (Endocrinol. Metab. 23):E27-E36.

48. Seaton, T. B., N. Coombe, and A. Mittelman. 1990. Tumor necrosis factor and hypermetabolism. Ann. Intern. Med. 112:75-76.

49. Tracey, K. J., H. Wei, K. R. Manogue, Y. Fong, D. G. Hesse, H. T. Nguyen, G. C. Kuo, B. Beutler, R. S. Cotran, A. Cerami, and S. F. Lowry. 1988. Cachectin/tumor necrosis factor induces cachexia, anemia, and inflammation. J. Exp. Med. 167:1211-1227.

50. Mahowald, M. W., M. L. Mahowald, S. R. Bundlie, and S. R. Ytterberg. 1989. Sleep fragmentation in rheumatoid arthritis. Arthritis Rheum. 32:974-983.

51. Roubenoff, R., L. W. Grimm, and R. A. Roubenoff. 1994. Albumin, body composition, and dietary intake in chronic inflammation. In Nutritional Assessment of Elderly Populations: Measure and Function. I. H. Rosenberg, editor. Raven Press, New York. In press.

52. Snyder, D. S., and E. R. Unanue. 1982. Corticosteroids inhibit murine macrophage Ia expression and interleukin-1 production. J. Immunol. 129:18031809.

53. Svenson, K. L. G., G. Lundqvist, L. Wide, and R. Hallgren. 1987. Impaired glucose handling in active rheumatoid arthritis: relationship to the secretion of insulin and counter-regulatory hormones. Metab. Clin. Exp. 36:940-943.

54. Svenson, K. L. G., G. Lundqvist, L. Wide, and R. Hallgren. 1987. Impaired glucose handling in active rheumatoid arthritis: effects of corticosteroids and antirheumatic treatment. Metab. Clin. Exp. 36:944-948.

55. Vaisman, N., V. A. Stallings, H. Chan, S. S. Weitzman, R. Clarke, and P. B. Pencharz. 1993. Effect of chemotherapy on the energy and protein metabolism of children near the end of treatment for acute lymphoblastic leukemia. Am. J. Clin. Nutr. 57:679-684.

56. McClave, S. A., S. C. Kaiser, B. M. Olash, L. K. Sexton, F. S. Priddy, and P. Hasselbacher. 1991. Effect of nonsteroidal anti-inflammatory drugs (NSAIDs) on energy metabolism: a prospective, double-blind, placebo-controlled study in normal volunteers. Gastroenterology. 100:536a. (Abstr.) 